\title{
UNIVERSAL EXFOLIATI $\backslash E$ DERMATITIS FROM SODIUM CACODYLATE
}

\author{
WILliaM ALLEN PUSEY; M.D. \\ CHICAGO
}

I recently observed a case of universal exfoliative dermatitis following injections of sodium cacodylate which was exactly analagous to similar cases following arsphenamin injections.

\section{REI'ORT OF CASE}

A druggist, a man aged 51, had had psoriasis for four years. The first attack cleared up under roentgen-ray treatment, and the second attack. two years later, was treated with roentgen rays and cleared up after four months. The present attack began two months ago. For this he had several roentgenray exposures, the last one about June 1 . When he came under my observation. July 15 , no signs of roentgen-ray effects were observable.

The first of June he went to a sanitarium for treatment of the psoriasis. There he had baths and special diet and the sort of routine treatment that sanitariums are apt to give in skin diseases. In addition he was given ten or twelve daily injections of sodium cacodylate, each $3 / 4$ of a grain. About June 22, a few days after the last injection, a redness of the skin appeared, which quickly became universal and developed to the degree which he showed three weeks later when he came into my hands.

At that time he presented a picture of a severe universal, dry, exfoliative dermatitis, quite similar in appearance to the Hebra type. The condition was absolutely universal. The skin was thickened, inelastic and red, and scaling profusely. On the hands and feet, the process was particularly intense. There was extreme hyperkeratosis of the palms and soles, and the condition was only less pronounced on the backs of the hands and feet. There was a good deal of burning of the general surface, and there were tenderness and discomfort on surfaces exposed to pressure.

He had been confined to his bed for two weeks previously, during which time he had shown an afternoon fever of from 101 to 102 degrees. He was much weakened and depressed but had not lost flesh. During the month he was under my care, being in a hospital most of the time, he showed some improvement. The hyperemia and the discomfort diminished, but the improvement was very slow. I should say the prospect is that ultimately the condition will disappear except perhaps for arsenical palms and soles.

The man's physical history was without significance. He had been in good health and, except for an attack of cystitis a few years ago, had had no important illness. He showed no evidences of any sort of sensitization and he gave no history of attacks of urticaria or erythema.

\section{COMMENT}

In my opinion, there are occasional cases in which the skin is hypersensitive to arsenic. I have seen one case of arsenical palms which followed injections of very small doses of arsenous acid (about $1 / 100$ grain) given as a tonic for about a week. Apparently, 
cases like this and the one herewith described are an expression of unusual susceptibility to arsenic. Such cases indicate a danger which the indiscriminate use of arsenic entails, and with which the profession apparently is not generally familiar. They constitute another reason why arsenic should not be given indiscriminately, as it so often is, in skin diseases. 